\title{
Sediment and water nutrients and microalgae in a coastal shallow lagoon, Ria Formosa (Portugal): Implications for the Water Framework Directive $\dagger$
}

\author{
Ana Brito, ${ }^{* a b}$ Alice Newton, ${ }^{b}$ Paul Tett ${ }^{a}$ and Teresa F. Fernandes ${ }^{a}$ \\ Received 12th May 2009, Accepted 9th September 2009 \\ First published as an Advance Article on the web 13th October 2009 \\ DOI: $10.1039 / b 909429 f$
}

Coastal shallow lagoons are considered to be highly important systems, which have specific biogeochemical cycles and characteristics. The assessment of sediment-water interfaces is essential to understand nutrient dynamics and to evaluate the vulnerability to eutrophication, especially in regions of restricted water exchange (RRE), such as the Ria Formosa, which have natural conditions for the accumulation of nutrients. Water samples were collected during the years of 2006 and 2007-08 for nutrients, chlorophyll $a$ and dissolved oxygen. Sediment samples were also collected for pore water nutrients and microphytobenthic chlorophyll $a$. Measurements of temperature, salinity and photosynthetic active radiation were also taken. The lagoon salinity is affected by occasional strong rainfall events. From comparison with previous work, a decrease in the nitrogen concentration in the water column can be observed, which may indicate an improvement of the water quality. Pore water nutrient concentrations were significantly larger than in the water column. Sediment-water exchanges are considered to be the most important processes in nutrient dynamics of the lagoon. Benthic microalgal biomass was also large compared with that of the phytoplankton. It represents about $99 \%$ of the total microalgal chlorophyll biomass of the system. The lagoon also contains (discontinuous) meadows of intertidal seagrass, but we did not study these. Due to the importance of sediments, the standard monitoring plans required by the Water Framework Directive may fail to track changes in the nutrient conditions and the microalgal responses to them.

\section{Introduction}

The human pressure on coastal areas has been increasing during the last few decades. The inputs of nitrogen $(\mathrm{N})$ and phosphorus (P) have experienced a great increase caused by anthropogenic activities. ${ }^{\mathbf{1} 2}$ The use of synthetic fertilizers, animal and human wastewaters and the combustion of fossil fuels are the most important sources of nitrogen. ${ }^{1,3}$ Phosphorus loads are mainly a consequence of agriculture and detergents inputs. ${ }^{2,4}$ As an example, the $\mathrm{N}$-enrichment of USA coastal waters was clearly

${ }^{a}$ School of Life Sciences, Edinburgh Napier University, Edinburgh, EH10 5DT, UK. E-mail: a.brito@napier.ac.uk; ana_brito@hotmail.com; Fax: +00441314552291; Tel: +00441314552350

${ }^{b}$ IMAR, FCT-Gambelas, University of Algarve, 8000-117 Faro, Portugal $\uparrow$ Part of a themed issue dealing with water and water related issues. identified as an important pollution problem. Two thirds of these waters were considered to be moderately to severely degraded due to nitrogen inputs. ${ }^{1}$ This problem may be even greater in places where the water renewal rate is lower, such as coastal lagoons. ${ }^{2}$ These lagoons are considered Regions of Restricted Exchange (RRE) due to their physical constraints in the water exchange with the sea. ${ }^{5}$ They have natural conditions for the accumulation of nutrients and therefore for the occurrence of eutrophication.

The Urban Waste Water Treatment Directive (UWWTD) which defines eutrophication as the 'enrichment of water by nutrients, ..., causing an accelerated growth of algae, ..., to produce an undesirable disturbance to the balance of organisms present in the water and the quality of the water concerned', and the Nitrate Directive of 1991, aimed to protect against nutrients from cities and farms. The Convention for the Protection of the

\section{Environmental impact}

The information in the article is of relevance to the understanding of environmental phenomena such as eutrophication, especially in shallow and confined water bodies. The article deals with the analysis of nutrient, chlorophyll and dissolved oxygen (DO) concentrations and sediment-water interactions in a shallow coastal lagoon. Nitrogen concentrations in the water column seem to have decreased from previous studies. Given the shallowness of the lagoon, sediment-water exchanges are considered to be the most important processes for nutrient dynamics. In addition, much of the primary productive capacity of the lagoon lies in the community of benthic microalgae, microphytobenthos. The article assesses the quality status of the lagoon according to European classifications and discusses how the implementation of the Water Framework Directive may fail to track important changes in nutrient conditions, as well as the algal responses to them. 
Marine Environment of the North-East Atlantic first established in 1992 has provided a useful approach for eutrophication assessment (OSPAR Commission'). The European Union has made a great effort to develop a legal tool for the regulation of water bodies, which regardless of not considering it directly, involves the implicit concept of eutrophication. This instrument, the Water Framework Directive $-\mathrm{WFD}^{7}$ of 2000 aims to reach good ecological quality of surface waters and groundwater, prevent future deterioration and thus achieve sustainable management of resources. This recent legislation has created the need to develop tools for the assessment of the quality status of water bodies. One example of this is the Assessment of Estuarine Trophic Status (ASSETS) methodology, described by Bricker et $a l^{8}$ and adapted to the Portuguese Tagus estuary by Ferreira et al. ${ }^{9}$ and to the Ria Formosa coastal lagoon by Nobre et al. ${ }^{10}$ However, the definition of undesirable disturbance is still the subject of much discussion and motivates the constant development of methodologies for the implementation of the WFD. ${ }^{11}$

The assessment of the ecological status requires a series of essential processes, such as the characterization of water bodies, the establishment of type-specific reference conditions, the intercalibration of elements, the development of monitoring programmes and finally the classification of water bodies based on Ecological Quality Ratios (EQRs). ${ }^{12}$ The WFD represents a significant progress towards the management of specific water bodies. For the very first time, systems may be characterized and evaluated according to their type, so that sites belonging to one specific type are more alike. The variability of biological parameters is smaller within types than between types. ${ }^{12}$ The ecological status of a water body is therefore evaluated by comparing measured values with site-specific reference conditions. Thus, the importance of the intercalibration of results for each specific typology is undeniable. Due to the complexity of these procedures, a Common Implementation Strategy (CIS) was developed to provide guidance on how to proceed to characterize sites, define reference conditions, implement an intercalibration exercise, etc., and finally on December 2008, the Commission Decision 2008/915/EC accomplished the harmonization of the ecological status assessment principles. ${ }^{13}$ For Ria Formosa, the standards for the chlorophyll high-good boundary were set to be $6-8 \mu \mathrm{g} \mathrm{L}^{-1}(90 \%$ ile) and for the good-moderate boundary were set to be $9-12 \mu \mathrm{g} \mathrm{L}^{-1}$ (90\%ile; Table 1$)$.

According to the WFD CIS, the assessment of the ecological status is mainly defined by the biological elements. The role of nutrients in this assessment is still unclear and flexibility has to be taken when establishing the nutrient background levels. For example, it may be appropriate for a Member State to relax the nutrient standards if there is consistent evidence that nutrient status is less than good but the biological status is good. Given that no background levels are established for Ria Formosa and due to the importance of evaluating the evolution of the system from the 1980s until now, we have used the EEA classification ${ }^{14}$ (Table 1), which was used in previous studies. ${ }^{3,15}$

In addition, environmental elements may be used differently (Directive 2000/60/EC). ${ }^{7}$ For example, the phytobenthos community should only be used for the assessment of river ecological quality (WFD, Directive 2000/60/EC). However, the WFD does not consider the interactions between sediments and the water column in shallow enclosed coastal waters, such as Ria Formosa lagoon. These interactions are considered very important in these systems and are discussed by Falcão, ${ }^{16}$ Falcão and Vale, ${ }^{17}$ Murray et al. ${ }^{18}$ and Wayland et al. ${ }^{19}$ Note that the WFD considers four water body types: rivers, lakes, transitional and coastal waters (until a distance of one nautical mile from land). Shallow enclosed coastal systems are a good example of how important the physical and biogeochemical processes are. The water volume is spread in a large area which gives a great importance to sediments. In fact, sediments may have a determinant role influencing the quality of the water column. ${ }^{18,19}$ They may act as sources or sinks of nutrients, depending on environmental conditions such as salinity, temperature and dissolved oxygen. ${ }^{16,20,21}$ The tidal exchange is also extremely important in the dynamics of each parameter. A large variation can be found in shallow lagoons from high water to low water for most of the parameters. ${ }^{3}$ Moreover, light penetrates to the bottom which provides suitable conditions for the development of important benthic algal communities. Their biomass in shallow systems may be significantly higher than phytoplankton biomass. Furthermore, their contribution to the total chlorophyll found in the water column may be up to $25 \%$ of the total annual primary production. ${ }^{22,23}$ Therefore, as discussed, the measurement of water column parameters in these systems may only provide a snapshot of the trophic status.

The aims of this study were to: 1) evaluate the short- and longterm temporal variation of pelagic nutrients and oxygen, which are part of the physicochemical quality elements described in the WFD as state indicators, and pelagic chlorophyll, which is part of the biological indicators relating to phytoplankton biomass; and 2) assess the importance of sediments in the system dynamics

Table 1 Quality status of coastal and marine waters, according to EEA (1999), OSPAR (2005) and Commission Decision (2008/915/EC)

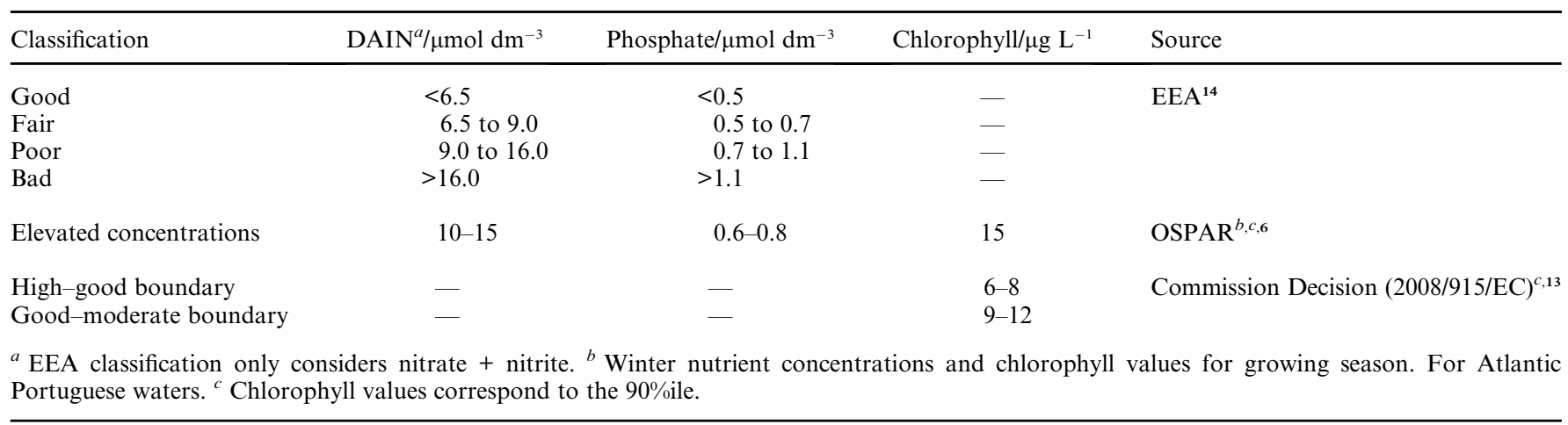


in terms of nutrients and chlorophyll. This paper is part of a study aimed at developing a model for nutrient cycling and its consequence for the biomass of phytoplankton and microphytobenthos in Ria Formosa. The model can, in the future, be used to explore the risk of eutrophication under different scenarios of nutrient enrichment and climate change. This part of the study reports observations that can be used to test the model and also to generate hypotheses that could be explored by the model.

\section{Methodology}

\subsection{Study site}

Ria Formosa is a shallow mesotidal lagoon located in the south of Portugal (Fig. 1). The WFD considers the lagoon as coastal waters of the North-East Atlantic (Directive 2000/60/EC of the European Parliament and Commission Decision 2005/646/EC). Ria Formosa has been a natural park since 1987. Within the international legislation it is part of the Natura 2000 European conservation network and it is a Ramsar protected area. The lagoon extends along the eastern part $\left(36^{\circ} 58^{\prime} \mathrm{N}, 8^{\circ} 02^{\prime} \mathrm{W}\right.$ to $\left.37^{\circ} 03^{\prime} \mathrm{N}, 7^{\circ} 32^{\prime} \mathrm{W}\right) .^{15}$ It has an extension of $55 \mathrm{~km}(\mathrm{E}-\mathrm{W}$, from Ancão to Cacela) and a maximum width of $6 \mathrm{~km}(\mathrm{~N}-\mathrm{S}) .{ }^{15}$ The lagoon covers an area of $100 \mathrm{~km}^{2}$ with a mean depth of $1.5 \mathrm{~m} .^{10,24}$ The tidal range varies from 1.3 on neap tides to $3 \mathrm{~m}$ on spring tides. The submerged area is estimated to be around $53 \mathrm{~km}^{2}$ at high water and $14-22 \mathrm{~km}^{2}$ at low water. Around half of the total area of the lagoon is constituted by salt marshes and mud flats. ${ }^{3}$ The water exchange with the sea, based on the tidal prism divided by the mid-water volume, was reported to be very significant, with around $50-75 \%$ of the water mass exchanged every tide cycle. ${ }^{5}$ However, recent work suggests small values of water residence, based on differences of salinity between seawater outside and inside the lagoon. ${ }^{25}$ The freshwater inputs are almost

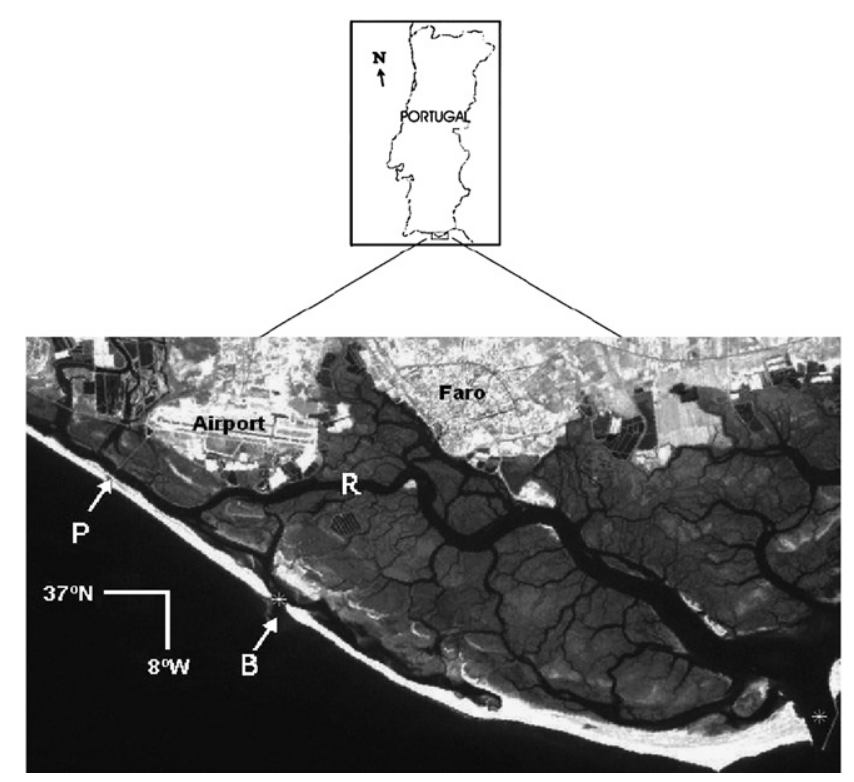

Fig. 1 Map of Ria Formosa showing sampling stations at $\mathrm{P}=$ Ponte and $\mathrm{R}=$ Ramalhete. The sampling station Beach is located near Ponte, but on the sea side. Adapted from Newton and Icely. ${ }^{53}$ negligible, especially in the summer, except during occasional heavy rainfall episodes. ${ }^{\mathbf{1 0}}$ The main sources of nutrients are point-source discharges from the population and the run-off from fertilized areas. The sediments may also be another important source of nutrients. ${ }^{18,20}$ The annual mean rainfall is around $634 \mathrm{~mm} .{ }^{15}$ The rainfall episodes are likely to occur more frequently during the winter.

Ria Formosa is a valuable socio-economic resource for the region. Industries linked with the lagoon, such as tourism, fisheries, aquaculture (especially shellfish) and salt extraction, are extremely important. $\mathrm{ICN}^{26}$ reported a production of 2740 tons of shellfish and 542 tons of fish. From these values, it is important to highlight that Ria Formosa represents $90 \%$ of the national production of Venerupis decussata and $81.7 \%$ of the national production of seabream. ${ }^{26}$ Shellfish harvesting in Ria Formosa causes an effective sediment disturbance.

\subsection{Sampling sites and schedule}

Sampling took place every two weeks, with few exceptions, from $10^{\text {th }}$ April to $18^{\text {th }}$ October during 2006 and from $15^{\text {th }}$ March 2007 to $20^{\text {th }}$ February 2008. Samples were collected from three sites: Ramalhete, Ponte and Beach (opposite to Ponte, in the sea side of the barrier, Fig. 1). Beach is considered an undisturbed site or with minor anthropogenic impacts. Ponte and Ramalhete are two intercalibration sites within the Water Framework Directive network (Directive 2000/60/EC of the European Parliament and Commission Decision 2005/646/EC). They are in the category of coastal waters due to the insignificant input of freshwater. Ramalhete, a site with medium/fine sand sediment, ${ }^{27,28}$ receives the effluent from a Urban Waste Water Treatment plant and is affected by its proximity to the airport and recreational activities caused mainly by boats. It is considered to be in the lower boundary of ecological quality, between Good and Moderate ecological status. ${ }^{29}$ Ponte, a site with muddy sand sediment, ${ }^{27,28}$ has the influence of the inputs from golf courses and intense agriculture from the western part of the lagoon. It is located in one of the main channels of the lagoon and has an ecological status that goes from High to Good. ${ }^{29}$

Water samples were collected for nutrient, chlorophyll and dissolved oxygen (not at the Beach site during 2006) analyses and sediment samples were collected for benthic chlorophyll and pore water nutrient analyses (once a month in 2007-08) when sediment was not immersed. Measurements of salinity and temperature were taken in situ using a WTW conductivity meter and Photosynthetic Active Radiation (PAR) values were also taken twice a month (see below). The sediment samples were not collected at the Beach and the PAR measurements were also not taken. This site is on the ocean coast, therefore is heavily influenced by wave action. Rainfall data were obtained from Direcção Regional de Agricultura e Pescas do Algarve (DRAP-Alg). The schedule was designed so that samples could be taken during low water and early in the morning (mostly between 6 and 8 am), when the dissolved oxygen concentration is lower.

\subsection{Physicochemical and biological components}

2.3.1 Photosynthetic active radiation (PAR) diffuse attenuation coefficient. On every sampling date, the PAR was measured 
at sea-bed level and at $0.25 \mathrm{~m}$ of depth in Ponte and Ramalhete to obtain the PAR diffuse attenuation coefficient using a Li-Cor (Li-192) Underwater Quantum sensor. This coefficient is useful to evaluate turbidity in shallow systems. The PAR diffuse attenuation coefficient was calculated using the function below, which follow the Beer-Lambert Law:

$$
K_{\mathrm{d}}=\frac{-\ln \left(\frac{E_{\mathrm{d}}\left(z_{1}\right)}{E_{\mathrm{d}}(0)}\right)}{z_{1}}
$$

Where $E_{\mathrm{d}}(z)$ is the PAR measurement at $z$ depth, $E_{\mathrm{d}}(0)$ is the PAR measurement when the sensor is just under the water surface, $K_{\mathrm{d}}$ is the PAR diffuse attenuation coefficient and $z$ is the depth.

2.3.2 Nutrients in the water column. Three samples of $0.5 \mathrm{dm}^{3}$ seawater were collected in each site on each sampling date. The samples were placed in a cool box and transported to the laboratory as soon as possible. The samples were immediately analysed, if possible, or frozen at $-20{ }^{\circ} \mathrm{C}$. Each sample was analysed in triplicates of $15 \mathrm{~cm}^{3}$ for ammonium-nitrogen, nitrite-nitrogen, nitrate-nitrogen, orthophosphate-phosphorus and silicate-silicon, following Grasshoff et al. ${ }^{30}$

2.3.3 Pore water nutrients. Three sediment cores were collected at Ponte and Ramalhete once a month. The corer had a diameter of $8 \mathrm{~cm}$ and $10 \mathrm{~cm}$ height. The core samples were placed in a plastic bag inside a cool box and were transported to the laboratory as soon as possible. In the laboratory, random sub-samples of each core were collected immediately, placed in $50 \mathrm{~cm}^{3}$ plastic tubes and centrifuged for $15 \mathrm{~min}$ at $4000 \mathrm{rpm}$. The overlying water was taken from all the tubes from each site and filtered using $0.45 \mu \mathrm{m}$ Nucleopore membranes. One sample of pore water was obtained from each site and diluted for later analysis of nutrients. Ammonium-nitrogen, nitrate-nitrogen, nitrite-nitrogen, orthophosphate-phosphorus and silicate-silicon were analysed following Grasshoff et al. ${ }^{30}$

Nutrient fluxes $(\phi)$ from pore water to the water column were calculated based on the following, Fick's first law of diffusion:

$$
\phi_{s}=-D_{m} \cdot \frac{\partial S}{\partial z} \cdot \frac{p}{\tau}
$$

Diffusion coefficient $\left(D_{m}\right)$ values were taken from Murray et al. ${ }^{18} 1.6416 \times 10^{-4} \mathrm{~m}^{2} \mathrm{~d}^{-1}$ for DAIN and $0.71194 \times 10^{-4} \mathrm{~m}^{2}$ $\mathrm{d}^{-1}$ for phosphate. The concentration gradient $(\partial S)$ was calculated subtracting the concentrations of the water column to the pore water concentrations. $z$ is the sediment-water interface distance, $0.001 \mathrm{~m}$ (thickness of the surface layer) $+0.001 \mathrm{~m}$ (thickness of the benthic layer), $p$ is porosity $(0.5)$ and $\tau$ is tortuosity of the sediment pores $(\approx 1.4$; following Jackson et $a{ }^{31}{ }^{31}$ ). Porosity was estimated considering the proportion of water after freeze-drying.

2.3.4 Pelagic chlorophyll. Three samples of $1.5 \mathrm{dm}^{3}$ of seawater were collected at each site on each sampling date. The samples were transported to the laboratory as soon as possible and $1 \mathrm{dm}^{3}$ was immediately filtered in a filtration slope prepared with glass microfibre filters $(47 \mathrm{~mm} \varnothing)$. One $\mathrm{dm}^{3}$ of seawater was filtered and the filters were placed in a plastic tube covered with aluminium foil. Ten $\mathrm{cm}^{3}$ of $90 \%$ acetone (buffered with sodium bicarbonate) were added to each tube. The filters were mashed up using a glass stick. The tubes were placed in a freezer at $-20^{\circ} \mathrm{C}$. After $24 \mathrm{~h}$, the tubes were centrifuged for $10 \mathrm{~min}$ at $3000 \mathrm{rpm}$. The supernatant was decanted to a $1 \mathrm{~cm}$ spectrophotometer cuvette and measured at $663 \mathrm{~nm}$ and $750 \mathrm{~nm}$. Two drops of $1.2 \mathrm{M}$ $\mathrm{HCl}$ were added to the cuvette and the sample was measured again at both wavelengths. Chlorophyll concentrations were calculated following Lorenzen's equations. ${ }^{32}$

2.3.5 Microphytobenthic chlorophyll. Six samples of sediment were collected from Ponte and Ramalhete using a Petri dish of $47 \mathrm{~mm}$ diameter and $13 \mathrm{~mm}$ height. A plastic card was used to manoeuvre underneath the sample. Samples were placed in a cool box and protected from sunlight. They were transported to the laboratory as soon as possible. In the laboratory, they were transferred to $50 \mathrm{~cm}^{3}$ plastic tubes wrapped in aluminium foil and placed in the freezer at $-20{ }^{\circ} \mathrm{C}$. All the samples were freeze-dried for $30 \mathrm{~h}$. The time necessary to freezedry the samples and the optimal procedure for benthic chlorophyll analysis of these samples were assessed by Brito et al. ${ }^{28}$ The weight of the sediment was determined after freezedrying. The solvent, $90 \%$ acetone for sand and $80 \%$ acetone for mud, buffered with sodium bicarbonate was added to each sample in a similar proportion of solvent volume to sediment weight and the tubes were stirred in the vortex. The samples were placed again in the freezer at $-20^{\circ} \mathrm{C}$ for $6 \mathrm{~h}$. The samples were then centrifuged and measured as described above for pelagic chlorophyll. A $10 \%$ dilution was carried out in $90 \%$ acetone so that spectrophotometric equations can be used for $80 \%$ acetone in muddy samples and to decrease the solution concentration of chlorophyll to permit a more reliable measurement. To calculate the chl $a$ content $\left(\mu \mathrm{g} \mathrm{g}^{-1}\right)$, the dried weight of sediment was used instead of the usual volume of filtered water used in water column chlorophyll assessments.

2.3.6 Oxygen. Three samples of seawater were collected using glass bottles at each site. The appropriate reagents were added in situ and the bottle protected from any air contact. ${ }^{30,33}$ The bottles were transported as soon as possible to the laboratory, where they were analysed following the method presented by Grasshoff et al.,${ }^{30}$ which is based on the method first proposed by Winkler. ${ }^{33}$ Oxygen saturation calculations were based on those of Carpenter. ${ }^{34}$

\subsection{Statistical analyses}

All statistical tests and numerical analyses were carried out using Minitab 14. Data were tested for normality and homoscedasticity of variance and parametric tests ( $t$-test) were conducted. Pearson's correlations were also investigated throughout this study.

Following the objective of the assessment of relationships between elements, a multiple regression approach was performed using data from each site. Data used for the multiple regression analysis were $\log (x)$ transformed, except temperature, which was conserved as real values. 

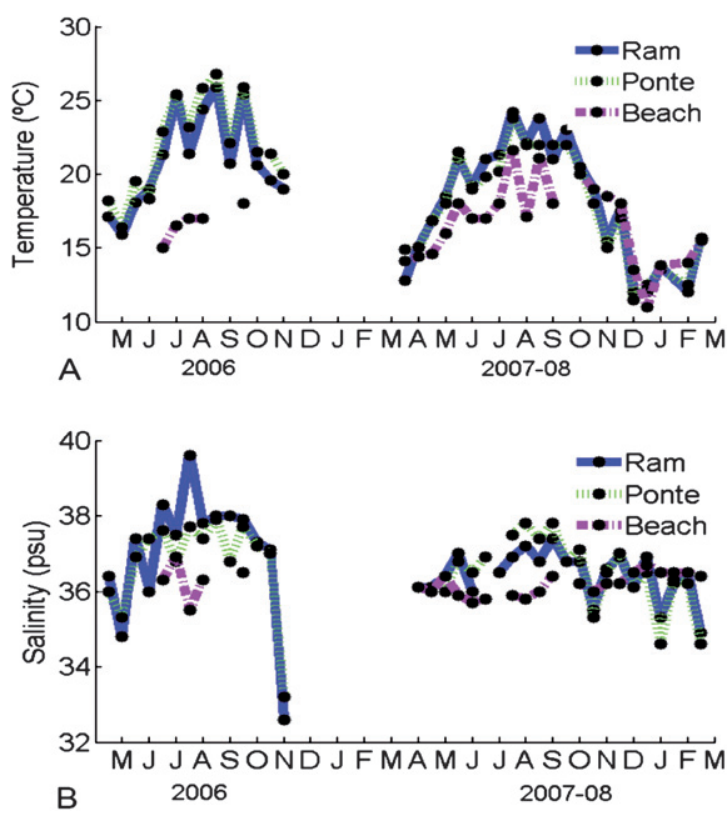

Fig. 2 Seasonal changes of temperature $\left({ }^{\circ} \mathrm{C} ; \mathrm{A}\right)$ and salinity (psu; B) from 2006 to 2007-08 at Ramalhete, Ponte and Beach.

\section{Results}

\subsection{Temperature and salinity}

Higher temperature and salinity values were found during the summer both in 2006 and 2007-08 (Fig. 2A and B). Beach was the site with lower temperatures and salinity. It was also the site that showed smaller variation throughout the years. In 2006, larger temperatures were observed during the summer because it was a warmer period compared with 2007. The low salinity values found within the lagoon, show that rainfall episodes were strong during the winter of 2006 and 2007-08 compared with both summers. Negative Pearson's correlations were found between salinity and rainfall (considering rainfall recorded during the 4 days before) at Ponte $(p<0.005)$ and Ramalhete $(p<0.001)$. The last salinity recorded in 2006 was taken after two days of heavy rain. Positive correlations (Pearson) were found between all sites for temperature and salinity in 2007-08 $(p<0.05)$ and in Ponte during $2006(p<0.05)$.

\subsection{PAR diffuse attenuation coefficient}

The agreement observed between the PAR diffuse attenuation coefficients measured at Ponte and Ramalhete is high (Table 2). The positive Pearson's correlation found was significant $(p<0.005)$. Ponte showed greater values throughout the year, except on the last sampling date. During November 2007, the greatest values were observed both in Ponte and Ramalhete. No correlations were found between PAR diffuse attenuation coefficient and salinity values or tidal range values $(p>0.05)$.

\subsection{Nutrients}

Concentrations of nitrite varied from 0 to $0.4 \mu \mathrm{M}$ in 2006 and 2007-08, except on the first day of sampling, when a peak was found at the three sites (Fig. 3A). Nitrite was not detectable during the summer of 2007. Ammonium concentrations varied frequently between 0 and $4 \mu \mathrm{M}$, with three exceptions, when concentrations almost reached $6 \mu \mathrm{M}$ (Fig. 3B). In 2008, most of the concentrations observed at Beach were small, except a peak in January 2008. Concentrations of nitrate varied from 0 to $4 \mu \mathrm{M}$ during most of the year of 2006 and 2007-08, except in November 2007, when a peak $(9 \mu \mathrm{M})$ was observed at Beach (Fig. 3C). Ramalhete was the site where the smallest concentrations of Dissolved Available Inorganic Nitrogen (DAIN) were observed (Fig. 3D). The variation found was from 0 to $6 \mu \mathrm{M}$, except in November 2007, when the concentrations reached $9 \mu \mathrm{M}$. The range of variation of phosphate was larger in 2006 (from 0.5 to $1.5 \mu \mathrm{M}$ ) than in 2007-08 (from 0 to $1 \mu \mathrm{M}$ ). Beach was the site where the smallest values were observed, especially in
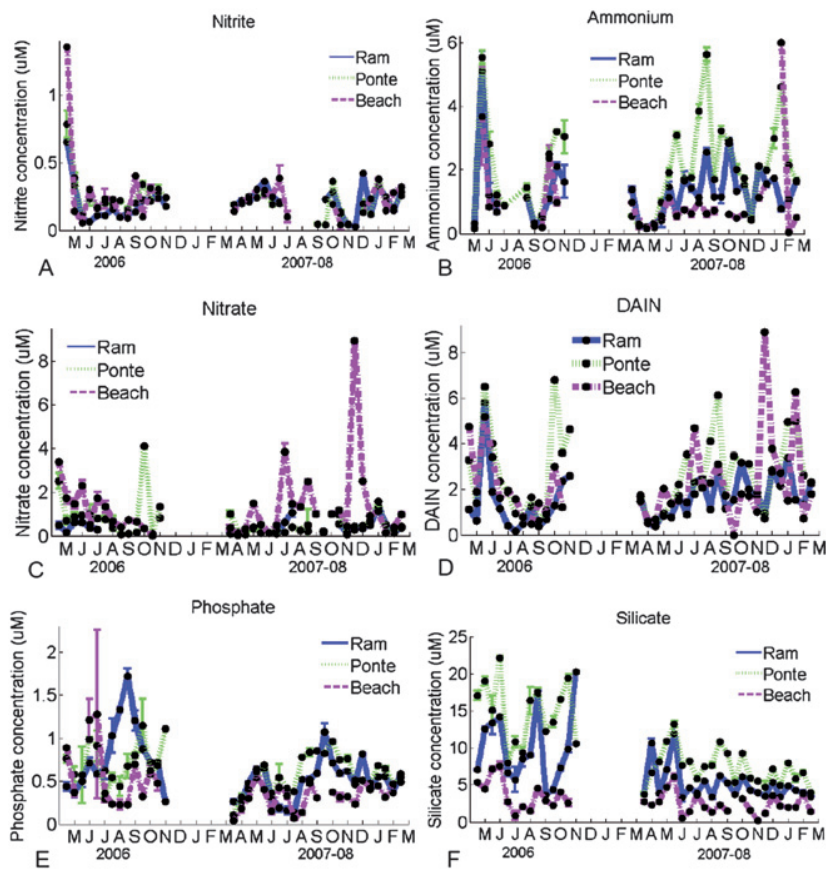

Fig. 3 Seasonal changes of nitrite ( $\mu \mathrm{M}$; A), ammonium ( $\mu \mathrm{M}$; B), nitrate $(\mu \mathrm{M} ; \mathrm{C})$, DAIN $(\mu \mathrm{M} ; \mathrm{D})$, phosphate $(\mu \mathrm{M} ; \mathrm{E})$ and silicate $(\mu \mathrm{M} ; \mathrm{F})$ in the water column during 2006 and 2007-08 at Ramalhete, Ponte and Beach.

Table 2 PAR diffuse attenuation coefficient $\left(K_{\mathrm{d}}, \mathrm{m}^{-1}\right)$ observed at Ramalhete and Ponte from March 2007 to February 2008

\begin{tabular}{|c|c|c|c|c|c|c|c|c|c|c|c|c|c|}
\hline & & \multicolumn{12}{|c|}{ Months } \\
\hline$K_{\mathrm{d}} / \mathrm{m}^{-1}$ & Ram & 0.25 & 0.79 & 0.59 & 0.57 & 0.53 & - & 0.9 & 0.59 & 1.10 & - & 0.66 & 0.90 \\
\hline & Ponte & 0.68 & 0.96 & 0.93 & 0.77 & 1.28 & - & 1.27 & 1.10 & 1.30 & 0.96 & 1.17 & 0.75 \\
\hline
\end{tabular}




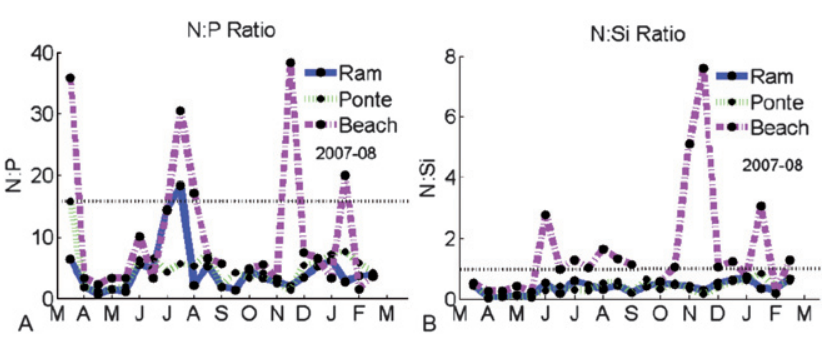

Fig. 4 N:P and N:Si ratios found in the water column during 2007-08 at Ramalhete, Ponte, and Beach.

2007-08 (Fig. 3E). Larger values of silicate concentrations were always found at Ponte and the smallest at Beach (Fig. 3F). The values varied approximately from 1 to $20 \mu \mathrm{M}$ in 2006 and between 1 to $15 \mu \mathrm{M}$ in 2007-08.

Positive Pearson's correlations were found between the values obtained at Ramalhete and Ponte for nitrite, ammonium, DAIN and silicate, during $2006(p<0.005)$. Positive Pearson's correlations were also found between the values obtained at Ramalhete and Ponte for all nutrients, during 2007-08 ( $p<0.05$ ). Beach was also positively correlated $(p<0.05)$ with the values of Ponte for nitrate (2006), with Ramalhete for phosphate (2007) and Ramalhete and Ponte for silicate (2007).

No significant differences were found between 2006 and 2007-08 data for nitrite, ammonium, nitrate and DAIN ( $t$-test, $p>0.05$ ). However, significant differences were found between 2006 and 2007-08 data for phosphate and silicate $(t$-test, $p<0.05)$.

The representation of the N:P ratio showed that inside the lagoon all the values are under 16, which is the reference Redfield number, except for one date (summer) in Ramalhete (Fig. 4A). Outside the lagoon, 4 points were found above the reference. The $\mathrm{N}: \mathrm{Si}$ ratio plot shows that inside the lagoon all the values are under 1, the Redfield reference, and outside the lagoon they are all above 1 (Fig. 4B). Inside the lagoon, Si concentrations are much larger compared with $\mathrm{N}$ concentrations.

All the concentrations of pore water nutrients obtained in this study were considerably larger than in the water column (Fig. 5A to F). Actually, DAIN concentrations in the water column were just $25 \%$ of the total concentrations of nitrogen in the lagoon (pore water + water column). Phosphate concentrations in the water column were estimated as being around $30 \%$ of the total and silicate concentrations around $60 \%$ of the total. Total concentrations of the water column were estimated considering mid-water values. Total concentrations of the pore water were estimated considering the area of the lagoon, the depth of the sediment layer and the porosity. A significant agreement was found between the nitrate values of Ponte and Ramalhete (Pearson's positive correlation: $p<0.05$ ). Ammonium is the compound that dominates the nitrogen reservoir of the sediment and clearly influences the Dissolved Available Inorganic Nitrogen (DAIN) concentrations. Large variations of concentration were found for almost all the nutrients throughout the year 2007-08. For phosphate, the concentrations were larger during the summer and silicate had a clear peak as well in August.

Fluxes estimated were $497 \mu \mathrm{mol} \mathrm{m}{ }^{-2} \mathrm{~h}^{-1}$ for DAIN and $37.4 \mu \mathrm{mol} \mathrm{m}^{-2} \mathrm{~h}^{-1}$ for phosphate.
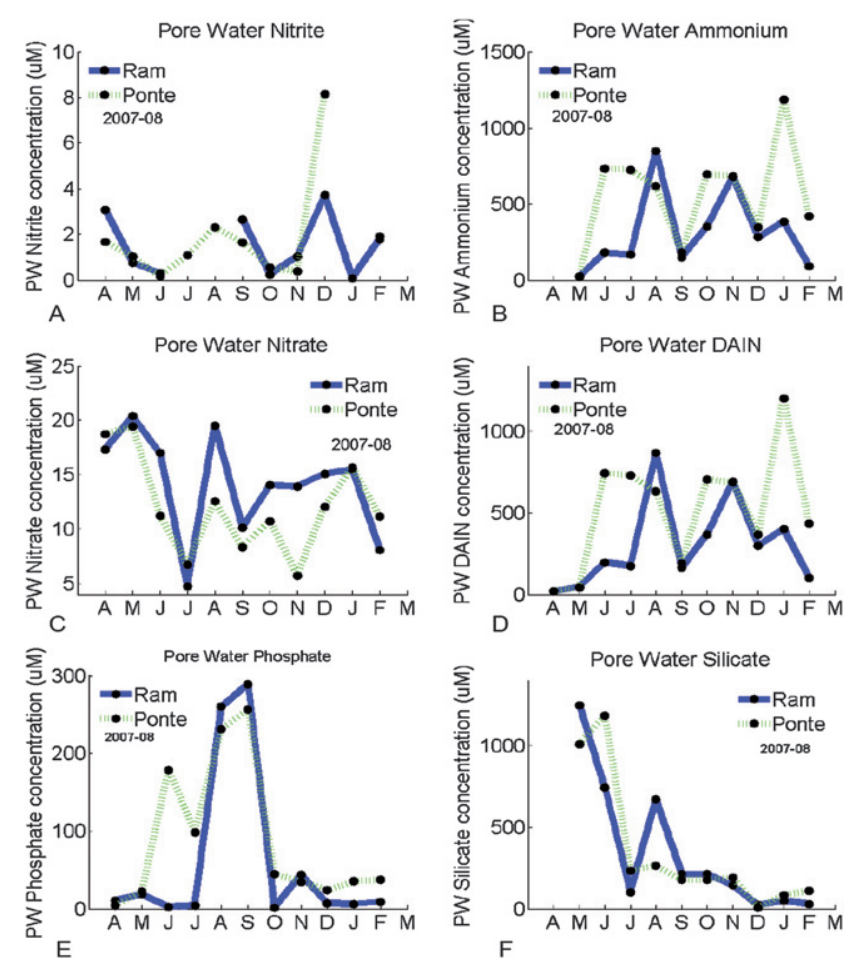

Fig. 5 Seasonal changes of nitrite $(\mu \mathrm{M} ; \mathrm{A})$, ammonium $(\mu \mathrm{M}$; B), nitrate $(\mu \mathrm{M} ; \mathrm{C})$, DAIN $(\mu \mathrm{M} ; \mathrm{D})$, phosphate $(\mu \mathrm{M} ; \mathrm{E})$ and silicate $(\mu \mathrm{M} ; \mathrm{F})$ in the pore water during 2007-08 at Ramalhete and Ponte.

\subsection{Chlorophyll}

During 2006, small concentrations of pelagic chlorophyll $a$ were found during the summer (Fig. 6A). However, the same trend was not found in 2007. A slight and constant decrease in the concentrations was found after June until February 2008. The concentration peaks found in 2006 were much higher than the ones found in 2007-08. The 90\%ile of chlorophyll $a$ found at Ponte and Beach in 2006 was below $5 \mu \mathrm{g} \mathrm{L}^{-1}$ and at Ramalhete was $7.6 \mu \mathrm{g} \mathrm{L}^{-1}$. In 2007 , the $90 \%$ ile found at the three sites was below $3 \mu \mathrm{g} \mathrm{L}{ }^{-1}$.

No clear pattern of variation can be pointed out for the benthic chlorophyll $a$ content found in 2006 and 2007-08 (Fig. 6-B). Large values were obtained during the summer of 2006 (from June to September) and after October at Ponte. However, in 2007-08, Ramalhete showed the larger values, although similar with the values observed at Ponte. The smallest values were observed at Ponte in the autumn and winter of 2007-08.

Pearson's correlations were not found $(p>0.05)$ in 2006 and 2007-08 between the pelagic and benthic chlorophyll $a$ concentrations for each site. In 2006, no correlations were found between pelagic and benthic $\operatorname{chl} a$ and the nitrite, nitrate, DAIN, phosphate and silica concentrations, except a positive correlation for nitrite concentration and pelagic chlorophyll $a$ concentration for Ramalhete $(p<0.05)$. In 2007 , negative correlations were found between pelagic chl $a$ and ammonium and DAIN at Ponte and Ramalhete $(p>0.05)$. No correlations were found between the benthic and pelagic chlorophyll and pore water nutrients $(p>0.05)$ for the period 2007-08.

In addition, the total pelagic chlorophyll concentrations of the system at mid water were calculated. Total benthic 

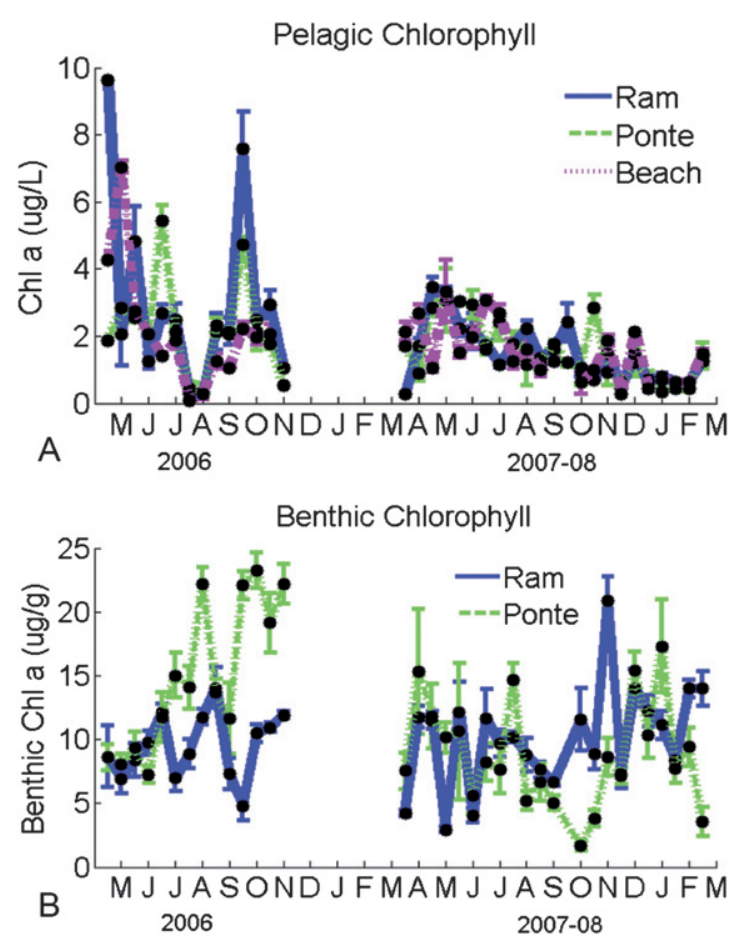

Fig. 6 Seasonal changes of pelagic chlorophyll $a$ during 2006 and 2007-08 ( $\mu \mathrm{g} \mathrm{L}^{-1}$; A) and benthic chlorophyll $a$ during the same period $\left(\mu \mathrm{g} \mathrm{g}^{-1} ; \mathrm{B}\right)$ at Ramalhete, Ponte and Beach.

concentrations were also calculated, considering that sediment surface is approximately constituted by $50 \%$ of sandy sediments and $50 \%$ of muddy sediments. ${ }^{35}$ Concentrations of pelagic chlorophyll were converted to $\mathrm{mg} \mathrm{m}^{-2}$ units so that they could be easily comparable with MPB concentrations. Pelagic chlorophyll amounts of about $132 \mathrm{~kg}$ (or $2.49 \mathrm{mg} \mathrm{m}^{-2}$ ) and benthic amounts of around $14250 \mathrm{~kg}$ ( or $269 \mathrm{mg} \mathrm{m}^{-2}$ ) were estimated for the whole lagoon, which means that pelagic chlorophyll is around $1 \%$ of the total chlorophyll existent in the lagoon.

\subsection{Oxygen}

Inside the lagoon, smaller concentrations of Dissolved Oxygen were generally found during the summer and autumn (Fig. 7). Ramalhete was the site where the smallest summer values were

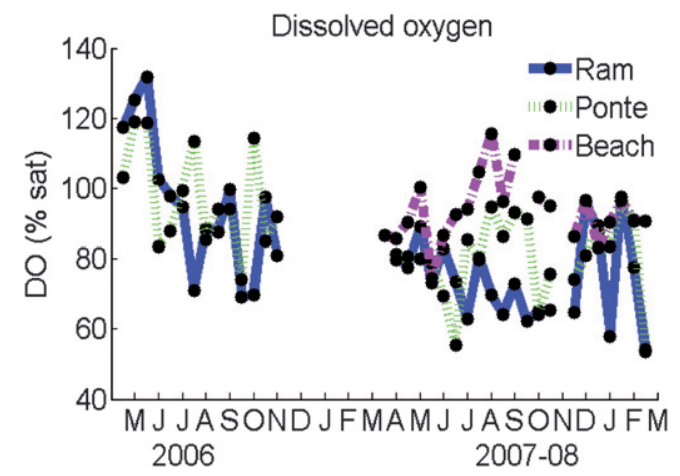

Fig. 7 Seasonal changes of Dissolved Oxygen (\% saturation) at Ramalhete, Ponte and Beach during 2006 and 2007-08. found, being almost $4 \mathrm{mg} \mathrm{L}^{-1}$ or between 60 and $80 \%$ of saturation. During the winter, larger values were found at Ramalhete. However, extremely small values were also observed $(55 \%)$. Ponte showed occasionally similar small values during the summer as well. The majority of saturation percentages at Ponte in 2007-08 were between 60 and $90 \%$. The 10\%ile at Ponte and Ramalhete during 2006 and 2007-08 was less than $5 \mathrm{mg} \mathrm{L}^{-1}$. Supersaturation (100-130\%) was observed during the winter of 2006 at both sites and at Ponte on summer and autumn. In 2007-08, supersaturation values were only observed at Beach.

Significant Pearson's correlations were found between the Dissolved Oxygen concentrations of Ponte and Ramalhete during $2006(p<0.05)$ and 2007-08 $(p<0.005)$. Significant correlations were also found between Ponte and Beach $(p<0.05)$ but not between Ramalhete and Beach $(p>0.05)$. As expected, significant Pearson's correlations were found between Temperature and Dissolved Oxygen in Ponte and Ramalhete $(p<0.05)$.

\subsection{Statistical analyses}

3.6.1 Multiple regression. A multiple regression approach revealed a significant relationship between phytoplankton and nitrite, temperature and oxygen at Ramalhete and between microphytobenthos and ammonium and silicate in pore water (Table 3). Multiple regression explained $83 \%$ of the microphytobenthos variability. At Ponte a significant relationship was only found between phytoplankton and microphytobenthos, although explaining just $12.4 \%$ of the variability. No significant relationships were found at Beach.

\section{Discussion}

\subsection{Influence of freshwater}

The salinity values presented in this study confirm the inclusion of Ria Formosa in the category of coastal water rather than transitional water, according to the Water Framework Directive. $^{7}$ The influence of freshwater is not dominant in this system, as discussed by Newton et al., ${ }^{3}$ Newton and Mudge ${ }^{15}$ and Loureiro et al. ${ }^{29}$ Salinity is closely related to temperature inside Ria Formosa. Typically, salinity is higher during the warm summer, due to evaporation and smaller in the cooler winter due to freshwater inputs from rainfall and run-off. ${ }^{29}$ The comparison between salinity and precipitation data (provided by the Direcção Geral de Agricultura e Pescas do Algarve), revealed

Table 3 Multiple regression of phytoplankton and microphytobenthos at Ramalhete, Ponte and Beach. Algal chlorophyll (Phyto and MPB) as a function of nitrate $\left(\mathrm{NO}_{2} ; \mu \mathrm{M}\right)$, temperature $\left(T ;{ }^{\circ} \mathrm{C}\right)$, dissolved oxygen $\left(\mathrm{O}_{2} ; \%\right.$ saturation), ammonium in sediments $\left(\mathrm{NH}_{4 \mathrm{sed}} ; \mu \mathrm{M}\right)$, silicate in sediments $\left(S i_{\text {sed }} ; \mu \mathrm{M}\right)$ and microphytobenthos $\left(M P B ; \mu \mathrm{g} \mathrm{g}^{-1}\right)$. Note that all data, except temperature is $\log (x)$ transformed

\begin{tabular}{|c|c|c|c|c|}
\hline & & Equation & $R^{2}$ & $p$ \\
\hline \multirow[t]{2}{*}{ Ram } & Phyto & $\begin{array}{l}\text { Phyto }=-1.64+0.681 \mathrm{NO}_{2}+ \\
0.0502 \mathrm{~T}+1.830 \mathrm{O}_{2}\end{array}$ & 47.2 & 0.001 \\
\hline & MPB & $\begin{array}{l}M P B=0.866+0.307 N H_{4 \mathrm{sed}}+ \\
\quad 0.283 S i_{\mathrm{sed}}\end{array}$ & 82.8 & 0.002 \\
\hline \multirow[t]{2}{*}{ Ponte } & Phyto & Phyto $=0.788-0.649 \mathrm{MPB}$ & 12.4 & 0.035 \\
\hline & MPB & $M P B=-0.301+0.0192 T+1.19 O_{2}$ & 11.8 & 0.054 \\
\hline Beach & Phyto & No significant regression found & - & - \\
\hline
\end{tabular}


that precipitation is clearly affecting salinity. During the winter of 2007-08 smaller salinity values, when compared with outside, were found after rainfall episodes. Temperature has obviously the same pattern with large values during the summer and smaller during the winter. It is of interest to highlight that freshwater inputs do not seem to affect the temperature of the lagoon. Probably, because the solar heating of water and sediments is stronger in the summer.

The PAR Diffuse Attenuation coefficient did not seem to be strongly influenced by the freshwater inputs. However, the rainfall introduces particles in suspension, which would affect the coefficient. The dilution effect is likely to be very important and therefore freshwater influence is not clear in the measurements. Moreover, other aspects may be affecting this coefficient, such as the re-suspension of the bottom sediments, which may be associated with the tide and winds, for example.

Nutrient concentrations, especially nitrogen also seem to be influenced by precipitation. In 2006, two clear peaks of DAIN were found in spring and in autumn. The first peak was caused by high ammonium concentrations $(5 \mu \mathrm{M})$ at Ramalhete and Ponte and the second was caused by high nitrate concentrations $(4 \mu \mathrm{M})$ in Ponte. These peaks are likely to be a consequence of the runoff from the surrounding areas, as confirmed by low values of salinity. Nevertheless, nitrogen peaks may also be affected by upwelling events outside the lagoon. In 2007-08 several DAIN peaks were observed throughout the year at Beach (caused by nitrate and ammonium) and Ponte (caused again by ammonium). The ammonium peak observed in January was also found at Beach $(6 \mu \mathrm{M})$ and Ponte $(5 \mu \mathrm{M})$. In this case, the source of ammonium seems to be the seawater and not run-off. Silicate, which is typically obtained by run-off, presents higher concentrations at Ponte, probably because of the greater influence of freshwater input on this site, compared with Ramalhete that is an inner channel.

\subsection{Nutrient, chlorophyll and oxygen conditions in the water column}

The nitrite, nitrate, ammonium and therefore DAIN concentrations are apparently very similar to each other during 2006 and 2007-08, except when peaks are observed. The phosphate concentrations in 2006 and 2007-08 seem to be slightly larger in the summer. An increase in the concentrations was expected due to the larger use of detergents by the increased population during this period. Ramalhete also shows high values of phosphate, probably because of its location, near to the water treatment plant, which only has secondary treatment. Silicate concentrations found during both sampling periods were relatively large, compared to the other nutrients. Our results are not totally in agreement with previous work. Newton et al. ${ }^{3}$ showed much larger values of DAIN concentration in the western part of the lagoon, where our study was focused (see Table 4). Newton and Mudge $^{36}$ obtained also larger values of nitrate concentrations, much larger than the ones obtained in the present study. The same authors also found silicate measurements at some sites which were 10 times larger. However, data used in both studies were collected in late $80 \mathrm{~s}$, prior to the opening of the artificial inlet in the west part of the lagoon, which was an important change to the water exchange in this part of the lagoon and consequently to the water exchange rate. Despite the proximity to towns, the source of these large concentrations was run-off. ${ }^{36}$ Loureiro et $a l .{ }^{29}$ found slightly larger nitrate values, however much more similar with ours. This work was carried out on the same conditions existent today, i.e., after the inlet opening. Much has been discussed in the literature about the export or import character of the lagoon for nutrients (e.g. Newton et al. ${ }^{3}$ Newton and Mudge ${ }^{36}$ ). Except for silicate, the similar values obtained for the different sites, Ramalhete, Ponte and Beach do not allow a clear assessment of possible relationships and evaluation of sources, given the distinctness of the sites. Silicate concentrations are clearly and consistently larger inside the lagoon in 2006 and 2007-08. Therefore, the lagoon may be considered as exporting this nutrient. Run-off may be an important source of silicates that can be trapped by the large population of benthic diatoms in the sediments. Mineralisation of accumulated material in the lagoon should also have an important role in silicate cycle. Occasional exports/imports of nitrogen compounds also take place whenever there is a peak in the concentrations, but it is not persistent. The nitrate peaks found in Beach during 2007 were probably caused by upwelling natural events. The lagoon also seems to be exporting phosphate to the outside. The unexpected small values of nitrate and DAIN are also of great interest. They could be a result of a larger demand from an increased biomass of algae, increased denitrification or could also be due to the improvement of the water quality by the decrease of nitrogen inputs in the lagoon or the increase of seawater exchange stimulated by the new inlet.

Table 4 Mean nutrient concentrations and mean nutrient fluxes obtained in several studies at Ria Formosa

\begin{tabular}{|c|c|c|c|c|c|c|c|c|c|}
\hline & Source & $\mathrm{NO}_{2}^{-}$ & $\mathrm{NO}_{3}^{-}$ & $\mathrm{NH}_{4}^{+}$ & $\mathrm{PO}_{4}^{3-}$ & $\mathrm{SiO}_{2}$ & Units & $\mathrm{N}: \mathrm{P}$ & Months \\
\hline & Loureiro et al. ${ }^{29}$ & 0.13 & 4.1 & 1.15 & 0.49 & 4.0 & $\mu \mathrm{M}$ & 12.0 & June $01-$ July 02 \\
\hline \multirow{4}{*}{ Pore water } & Falcão ${ }^{16 a}$ & - & 15 & 100 & 10 & 150 & $\mu \mathrm{M}$ & - & May 93-March 94 \\
\hline & Murray et al. ${ }^{18}$ a & 2 & 50 & 400 & 100 & - & $\mu \mathrm{M}$ & $\approx 4.5$ & June-August 04 \\
\hline & Serpa et al. ${ }^{35 a}$ & 35 & & 155 & 25 & - & $\mu \mathrm{M}$ & $\approx 7.6$ & March-December \\
\hline & Present study & 1.47 & 13.02 & 437.9 & 73.5 & 343.8 & $\mu \mathrm{M}$ & $\approx 6$ & March 07-March 08 \\
\hline & Present study & 497 & & & 37.4 & - & $\mu \mathrm{mol} \mathrm{m}{ }^{-2} \mathrm{~h}^{-1}$ & - & March 07-March 08 \\
\hline
\end{tabular}


One of the elements considered in the WFD to assess the ecological quality is the 'nutrient condition', which should not only include the concentrations but also ratios between nutrients. The N:P ratio values obtained are mostly below the Redfield ratio inside the lagoon, which may indicate a nitrogen limitation in this system. Although the use of this ratio to evaluate the limiting nutrient is still a subject of great discussion, especially in the presence of large concentrations, this can be a useful indicator (Falcão, ${ }^{16}$ EEA, ${ }^{14}$ OSPAR,${ }^{6}$ Newton et al.,${ }^{3}$ Neill,${ }^{37} \mathrm{Kim}$ et $a l^{38}$ ). Nitrogen limitation is also supported by previous experimental studies such as Edwards et al. ${ }^{39}$ and Loureiro et al. ${ }^{40,41}$ The $\mathrm{N}: \mathrm{Si}$ ratio, which can be very important for organisms with silicate requirements such as diatoms, reflects clearly the large and available concentrations of silicate inside the lagoon compared with nitrogen. Outside the lagoon, the ratio can have higher values, which may express a silicate limitation during upwelling events. This can influence the algal species composition and balance.

The pelagic chlorophyll $a$ concentrations observed in Ria Formosa are within the range found previously by Falcão, ${ }^{16}$ Falcão and Vale ${ }^{17}$ and Newton et al. ${ }^{3}$ These values are actually smaller than the concentrations found in other European RREs. ${ }^{5}$ However, during 2006, occasional peaks were observed in spring and late summer. In both sampling periods, the concentrations were smaller in the winter, when the irradiation decreases. In the summer of 2006, a strong decrease was observed, which may be related to an increase in grazing pressure. ${ }^{29,41}$ The non-existence of any positive strong correlation between chlorophyll and nutrients in the water column indicates that several processes may affect chl $a$, such as the re-suspension of the surfacial part of the large benthic algal community.

The warmer periods are critical for dissolved oxygen. Moreover, the oxygen saturation percentages are extremely important in this temperature and salinity variable system to express oxygen availability. In general terms, the observed saturation percentages confirmed the conclusions obtained from the dissolved oxygen concentrations. As expected, the smaller values were obtained in the summer period both in 2006 and 2007-08. The critical DO value is variable for different organisms, but generally $5 \mathrm{~m} \mathrm{~L}^{-1}$ is considered critical (biological stress) for most vertebrates. ${ }^{8}$ Especially in 2007-08, the smallest values were obtained at Ramalhete (4-5 $\mathrm{mg} \mathrm{L}^{-1}$ and $60-80 \%$ of oxygen saturation) and the largest at Beach (6-8 $\mathrm{mg} \mathrm{L}^{-1}$ and $80-120 \%$ of oxygen saturation). At Ramalhete most of the values were under the critical value after May (below $5 \mathrm{mg} \mathrm{L}^{-1}$ and $80 \%$ of oxygen saturation). These low values are in agreement with Mudge et al.$^{42}$ but not with Falcão ${ }^{16}$ and Falcão and Vale. ${ }^{17}$ The divergence may be due to the time of sampling. Both our results and the ones of Mudge et al. ${ }^{42}$ were obtained early in the morning, when the oxygen levels are lower due to respiration and oxidation overnight. Newton and Mudge $^{36}$ also presented higher percentages of oxygen saturation during low water. Besides being affected by the smaller exchange rate, the water in the inner channel Ramalhete may also be influenced by the oxygen-consuming effluents. ${ }^{42}$

\subsection{Nutrient and chlorophyll conditions in the sediments}

The concentrations of all nutrients studied here were significantly larger in the pore water than in the water column
(Table 6). These results have been widely reported in the literature for coastal systems in general, but also for Ria Formosa. ${ }^{16,18,19,35,43,44}$ The larger nitrogen concentrations observed in the sediments suggest that the production is faster than the release to the water column, which can happen by molecular diffusion, tide influence or bioturbation, for example. ${ }^{16,18,45}$ Falcão ${ }^{16}$ and Serpa et al. ${ }^{35}$ observed larger values of ammonium during the summer in Ria Formosa. Our results agree with this pattern but these high values were sustained after summer. The increase of ammonium in the summer is mainly due to the increase of the microbial processes, which are temperature dependent. ${ }^{16,21}$ The large concentrations observed may therefore be a consequence of the high temperatures after the summer in Portugal. The concentrations of the nitrogen compounds found were larger than the ones found by Falcão ${ }^{16}$ and similar to the concentrations found by Murray et al. ${ }^{18}$ except for ammonium, which are slightly larger. The larger phosphate concentrations found in the summer were also reported by $\mathrm{Falcão}^{16}$ however in a smaller magnitude. The phosphate is accumulated during the winter and released in the summer, as it is affected by anoxia. The temperature is the factor that mainly affects the release of silicate, so larger concentrations are normally observed in the summer, as reported by Falcão. ${ }^{16}$ Our results show larger concentrations in late spring and summer in accordance with what was discussed.

The range of variation of benthic chlorophyll was roughly within the range reported for Ria Formosa ${ }^{46,47}$ and for other sites. ${ }^{48,49}$ The content of chlorophyll seems to be larger now than in 1987. This increase is in agreement with, and may be supported by, the larger pore water concentrations ${ }^{50}$ in comparison with the ones found in the past, especially for ammonium, which is preferentially taken by microphytobenthos. The higher biomass of MPB will also contribute to a larger uptake of nutrients from the water column.

\subsection{Importance of sediments in shallow lagoon systems}

The large concentrations of pore water nutrients indicate that sediments are important nutrient stocks for the whole lagoon. Therefore there is a need to quantify the molecular diffusion to quantify the influence of sediments to water column quality (Table 4). Falcão ${ }^{16}$ and Murray et al. ${ }^{18}$ used Fick's law of diffusion to calculate the molecular diffusion. The largest value for ammonium obtained by Falcão ${ }^{16}$ was $97.5 \mu \mathrm{mol} \mathrm{m}{ }^{-2} \mathrm{~h}^{-1}$. Murray et al. ${ }^{18}$ obtained a maximum that was almost ten times larger, $821 \mu \mathrm{mol} \mathrm{m}{ }^{-2} \mathrm{~h}^{-1}$. For nitrate + nitrite, Falcão ${ }^{16}$ found a maximum value of $45.25 \mu \mathrm{mol} \mathrm{m}^{-2} \mathrm{~h}^{-1}$, while Murray et al. ${ }^{18}$ found a maximum of $170 \mu \mathrm{mol} \mathrm{m} \mathrm{m}^{-2} \mathrm{~h}^{-1}$ just for nitrate. Our results are very similar to the results obtained by Murray et al..$^{18}$ and confirm the importance of these fluxes to the lagoon system. For phosphate, the maximum obtained by Murray et al. ${ }^{18}$ was $123 \mu \mathrm{mol} \mathrm{m}{ }^{-2} \mathrm{~h}^{-1}$ and the range was from $10 \mu \mathrm{mol} \mathrm{m} \mathrm{m}^{-2} \mathrm{~h}^{-1}$. Falcão ${ }^{16}$ observed a maximum of $35.5 \mu \mathrm{mol} \mathrm{m}^{-2} \mathrm{~h}^{-1}$. Once more, our results were similar to Murray et al., ${ }^{18}$ as stated in Table 4. For silicate, the maximum obtained by Falcão ${ }^{16}$ was $162.60 \mu \mathrm{mol}$ $\mathrm{m}^{-2} \mathrm{~h}^{-1}$. These values give a clear indication of the importance of sediments. Falcão ${ }^{16}$ also estimated the total balance of nutrients in Ria Formosa and showed how the water-sediment exchange is the principal component. 
MPB represents approximately $99 \%$ of the total microalgal chlorophyll of this lagoon system, which confirms the importance of the benthic community. They act as consumers of benthic nutrients, decreasing the potential flux estimated above. In this way, they uptake nutrients that otherwise would go into the water column. Due to their high proportion in relation to pelagic chlorophyll, their influence in the water column by resuspension is likely to be large. Therefore, MPB plays a key role in the interactions between sediments and the water column and possibly in the determination of the ecological water quality of the lagoon.

The strong relationship between microphytobenthos and two nutrients (ammonium and silicate) of the pore water provides another indication of the importance of MPB to the consumption of pore water nutrients and the influence of these nutrients to the MPB community itself. This result is extremely important since it represents about $83 \%$ of the total variability explained. In fact, a strong relationship between benthic chlorophyll and pore water nutrients was previously indicated and discussed by Facca and Sfriso $^{50}$ for the Venice lagoon. The great importance of nutrients in supporting the benthic microalgae biomass should be further investigated in the future. The prediction of phytoplankton from MPB biomass is also very interesting. Although representing a small percentage of the variability, this suggests the importance of the re-suspension of benthic algal cells for the total chlorophyll in the water column.

\subsection{Assessment of the quality status of Ria Formosa}

Our assessment of the quality status of this lagoon system, in terms of nutrients, followed the EEA ${ }^{14}$ and the OSPAR ${ }^{6}$ classifications (Table 1). This was an attempt at clarifying the system given that no nutrient background concentrations or thresholds exist at the moment for Ria Formosa. Harmonized methodologies at the EU level should be followed in the future and the role of nutrients in the assessment of the ecological status has to be clarified. Using EEA standards also allows a comparison with the nutrient status found in previous papers. According to our results the quality status of nitrate + nitrite was never worse than 'Fair' in 2006 and 2007-08 (following EEA ${ }^{14}$ ). In fact, in 2006 it was always classified as 'Good' and in 2007-08 there was only one instance when that status was not obtained (November). This represents an improvement on water quality, compared with the results of Newton et al. ${ }^{3}$ In 2006 the quality status based on phosphate was most of the time 'Fair' or 'Poor'. However in 2007-08 it was most of the time 'Good' or 'Fair', which was the same as described by Newton et al. ${ }^{3}$ Following the OSPAR classification, ${ }^{6}$ DAIN concentrations are 'below elevated level' and phosphate concentrations are 'above elevated level'.

Following the criteria provided by the Commission Decision 2008/915/EC, ${ }^{13}$ Ria Formosa had high ecological quality in 2006 and 2007, except at Ramalhete in 2006, when the phytoplankton element indicated that it was within the high-good boundary. ${ }^{13}$ Under OSPAR procedure, ${ }^{6}$ the chlorophyll measurements in the lagoon were 'below elevated concentrations'.

The overall classification of Ria Formosa following the OSPAR procedure would seem to be a 'Potential Problem Area' in terms of eutrophication. The phosphate concentrations are above the threshold and oxygen levels indicate oxygen deficiency in the lagoon. However, since the limiting element is considered to be nitrogen, the elevated concentrations of phosphate may not have a significant expression in the eutrophication process. It is not clear that the oxygen deficiency is a result of nutrient-stimulated production in the Ria Formosa.

\subsection{Implications to the approach taken by the WFD}

The first problematic issue that we want to address here is related to the definition of surface water categories within the WFD, especially the transitional and coastal waters. Transitional waters are defined in the WFD as 'bodies of surface waters in the vicinity of river mouths which are partially saline in character as a result of their proximity to coastal waters but which are substantially influenced by freshwater'. Coastal waters are defined as 'surface water on the landward side of the line, every point of which is at a distance of one nautical mile on the seaward side from the nearest point of the baseline from which the breadth of territorial waters is measured, extending where appropriate up to the outer limit of transitional waters'. Salinity and morphology are the obvious criteria used for these definitions. As already discussed by McLusky and Elliott, ${ }^{51}$ there are some unclear situations, such as the Baltic Sea, which has brackish waters and still is considered within the coastal waters typology and some coastal lagoons as Ria Formosa, which are clearly not open coastal waters but at the same time not measurably influenced by freshwater inputs and still are considered within the coastal waters typology. The distinction between the different categories should be ecologically relevant. Following the salinity criterion, Ria Formosa is correctly classified. However, being within the coastal waters category means that no monitoring of fish communities is needed. The high ecological importance of the lagoon as a nursery system for fish communities ${ }^{52}$ is therefore not considered.

Secondly, we want to discuss the relevance of our findings, in terms of the importance of sediments to the implementation plans of the WFD. The ecological status of coastal water bodies is required to be assessed under the WFD guidelines, following physicochemical and biological criteria. The annex $\mathrm{V}$ of the WFD specifies the 'physicochemical quality elements' as pelagic nutrient concentrations, oxygen concentration and transparency and of three 'biological quality elements' as phytoplankton, macroalgae and angiosperms, and benthic invertebrate fauna. Therefore, no monitoring of microphytobenthos, as well as nutrients within the benthic system, is expected. Our study indicates that most of the primary productive capacity lies on the microalgae community living in the sediment surface. It is also within the sediments where the main stock of nutrients within the lagoon can be found. The standard monitoring programmes required for the implementation of the Directive, may fail to track relevant changes in the nutrient conditions and dynamics, as well as the algal responses to them.

\section{Conclusions}

The quality status of the water column in Ria Formosa, especially regarding phosphate, is still considered to be lower than the target objective ('Good' status) defined by the Water Framework Directive for 2015 , following the $\mathrm{EEA}^{14}$ classification. The 
OSPAR procedure ${ }^{6}$ also indicated that phosphate levels were above the threshold. However, an improvement in water quality was observed, compared with previously published results. This may be due to an increase of the benthic algal community, which contributes to the nutrient retention in the sediments and uptakes nutrients from the water column. Nevertheless, this assessment is merely indicative and present conditions should be re-evaluated against site-specific reference conditions. The microphytobenthos communities are extremely important in this system. They represent the majority of photosynthetic elements, being responsible for about $99 \%$ of the microalgal chlorophyll of the system. Their contribution to the pelagic chlorophyll concentrations may therefore be large, due to re-suspension. The small levels of dissolved oxygen observed in the morning may be critical for fauna populations and should be closely followed. The release of nutrients from sediments may also be influenced by oxygen concentration. This problem is even greater in the inner channels of the lagoon, where the residence time of water is longer leading to a decrease in oxygen.

Due to the importance of pore water nutrients and benthic algal communities, the implementation plan of the Water Framework Directive should be carefully assessed as it may fail to track nutrient-driven changes amongst the primary producers. In addition, due to the extreme low values of DO and similar to what has previously been suggested by Ferreira et al., ${ }^{9}$ shorter sampling intervals, compared with the 3 months proposed by the WFD, could be considered.

\section{Acknowledgements}

Ana Brito was funded by a portuguese $\mathrm{PhD}$ grant from FCT (POCI $2010 \mathrm{BD} / 21525 / 05$ ) and an initial studentship (from October to December 2005) from Edinburgh Napier University. This work was also funded by the European Framework 6 specific targeted research project ECASA (DG Fish Contract 006540).

\section{References}

1 R. Howarth and R. Marino, Limnol. Oceanogr., 2006, 51, 364-376.

2 D. Schindler, Limnol. Oceanogr., 2006, 51, 356-363.

3 A. Newton, J. Icely, M. Falcão, A. Nobre, J. P. Nunes, J. G. Ferreira and C. Vale, Cont. Shelf Res., 2003, 23, 1945-1961.

4 J. P. Jensen, A. R. Pederson, E. Jeppensen and M. Søndergaard, Limnol. Oceanogr., 2006, 51, 791-800.

5 P. Tett, L. Gilpin, H. Svendsen, C. P. Erlandsson, U. Larsson, S. Kratzer, E. Fouilland, C. Janzen, J. Lee, C. Grenz, A. Newton, J. G. Ferreira, T. Fernandes and S. Scory, Cont. Shelf Res., 2003, 23, 1635-1671.

6 OSPAR Commission, Common procedure for the identification of the eutrophication status of the OSPAR marine area, OSPAR Convention for the protection of the marine environment of the north-east Atlantic, 2005, pp. 36.

7 C.E.C., Council Directive of 23 October 2000, establishing a framework for Community action in the field of water policy (2000/60/EC), Official Journal of the European Communities, 2000, L327, 1-72.

8 S. Bricker, J. G. Ferreira and T. Simas, Ecol. Modell., 2003, 169, 39-60.

9 J. G. Ferreira, C. Vale, C. V. Soares, F. Salas, P. E. Stacey, S. B. Bricker, M. C. Silva and J. C. Marques, Environ. Monit. Assess., 2007, 135, 195-216.

10 A. M. Nobre, J. G. Ferreira, A. Newton, T. Simas, J. D. Icely and R. Neves, J. Mar. Syst., 2005, 56, 375-390.
11 P. Tett, R. Gowen, D. Mills, T. Fernandes, L. Gilpin, M. Huxham, K. Kennington, P. Read, M. Service, M. Wilkinson and S. Malcom, Mar. Pollut. Bull., 2007, 55, 282-297.

12 A. Heiskanen, W. van de Bund, A. C. Cardoso and P. Nõges, Water Sci. Technol., 2004, 49, 169-177.

13 European Communities, Commission Decision 2008/915/EC, Official Journal of the European Communities, 2008, L332, 20-44.

14 EEA, Nutrients in European ecosystems. Topic Report N. 4/1999. European Environmental Agency, 1999, 156pp.

15 A. Newton and S. Mudge, Portugal, Estuarine, Coastal Shelf Sci., 2003, 57, 73-85.

16 M. Falcão, PhD Thesis, University of Algarve, Portugal, 1996.

17 M. Falcão and C. Vale, Ciencias Marinas, 2003, 29, 425-433.

18 L. Murray, S. Mudge, A. Newton and J. Icely, Biogeochemistry, 2006, 81, 159-178.

19 D. Wayland, D. P. Megson, S. Mudge, J. Icely and A. Newton, Environ. Forensics, 2008, 9, 231-239.

20 M. Falcão and C. Vale, Hydrobiologia, 1990, 207, 137-146.

21 I. Gönenç and J. Wolflin, Coastal lagoons: ecosystem processes and modeling for sustainable use and development, CRC Press, Boca Raton, 2005, pp. 500.

22 F. Colijn, Neth. J. Sea Res., 1982, 15, 196-216.

23 F. Colijn and V. de Jonge, Mar. Ecol.: Prog. Ser., 1984, 14, 185-196.

24 R. Asmus, M. Sprung and H. Asmus, Hydrobiologia, 2000, 436, $217-235$.

25 S. Mudge, J. Icely and A. Newton, Estuarine, Coastal Shelf Sci., 2008, 77, 278-284.

26 ICN (Instituto Conservação da Natureza), Revisão do Plano de Ordenamento do Parque Natural da Ria Formosa, 2002. Available in: http://www.icnb.pt/.

27 A. Brito, A. Newton, P. Tett and T. Fernandes, J. Coastal Res., 2009, SI56, 381-384.

28 A. Brito, A. Newton, P. Tett and T. Fernandes, J. Int. Ecosyst. Assess. Sci., 2009, 4, 42-54.

29 S. Loureiro, A. Newton and J. Icely, Estuarine, Coastal Shelf Sci., 2006, 67, 382-398.

$30 \mathrm{~K}$. Grasshoff, M. Ehrhardt and K. Kremling, Methods of seawater analysis, Verlag Chemie, Weinheim, 1983, pp. 419.

31 P. Jackson, K. Briggs, R. Flint, R. Holyer and J. Sandidge, Mar. Geol., 2002, 182, 55-76.

32 G. Lorenzen, Limnol. Oceanogr., 1967, 12, 343-346.

33 L. W. Winkler, Ber. Dtsch. Chem. Ges., 1888, 21, 2842-2855.

34 J. Carpenter, Limnol. Oceanogr., 1966, 11, 264-277.

35 D. Serpa, M. Falcão, P. Duarte, L. C. Fonseca and C. Vale, Biogeochemistry, 2007, 82, 291-304.

36 A. Newton and S. Mudge, Estuarine, Coastal Shelf Sci., 2005, 62, 405-414.

37 M. Neill, Mar. Pollut. Bull., 2005, 50, 945-955.

38 H. Kim, S. Hwang, J. Shin, K. An and C. G. Yoon, Hydrobiologia, 2007, 581, 255-267.

39 V. Edwards, J. Icely, A. Newton and R. Webster, Estuarine, Coastal Shelf Sci., 2005, 62, 391-403.

40 S. Loureiro, A. Newton and J. Icely, Sci. Mar., 2005, 69, 323-341.

41 S. Loureiro, A. Newton and J. Icely, J. Exp. Mar. Biol. Ecol., 2008, 359, $118-125$.

42 S. Mudge, J. Icely and A. Newton, J. Environ. Monit., 2007, 9, 1194-1198.

43 Y. Lerat, P. Lasserre and P. Corre, J. Exp. Mar. Biol. Ecol., 1990, 135, $135-160$.

44 J. Forja, J. Blasco and Gómez-Parra, Estuarine, Coastal Shelf Sci., 1994, 39, 127-141.

45 D. Di Toro, Sediment Flux Modeling, John Wiley and Sons, New York, 2001, pp. 624.

46 A. Amorim-Ferreira, BSc thesis, University of Lisbon, Portugal, 1987.

47 A. Brito, A. Newton, P. Tett and T. Fernandes, Estuarine, Coastal Shelf Sci., 2009, 83, 67-76.

48 C. Riaux-Gobin and P. Bourgoin, J. Mar. Syst., 2002, 32, 295-306.

49 S. Hedtkamp, PhD thesis, Christian Albrechts University, Germany, 2005. Available in: http://deposit.ddb.de/.

50 C. Facca and A. Sfriso, Estuarine, Coastal Shelf Sci., 2007, 75, 35-49.

51 D. S. McLusky and M. Elliott, Estuarine, Coastal Shelf Sci., 2007, 71, 359-363.

52 M. Santos and C. Monteiro, Fish. Res., 1997, 30, 33-41.

53 A. Newton and J. Icely, J. Coastal Res., 2006, SI39, 1346-1350. 